Submitted to

DOI: 10.1002/adfma.((please add manuscript number))

Deciphering Limitations To Meet Highly Stable Bio-Hybrid Light-Emitting Diodes By Verónica Fernández-Luna, Daniel Sánchez-deAlcázar, Juan P. Fernández-Blázquez, Aitziber L. Cortajarena, Pedro B. Coto, and Rubén D. Costa*

Verónica Fernández-Luna, Juan P. Fernández-Blázquez, and Dr. Rubén D. Costa

IMDEA Materials Institute, Calle Eric Kandel 2, 28906 Getafe, Spain

E-mail: ruben.costa@imdea.org

Verónica Fernández-Luna

Departamento de Física de Materiales Universidad Autónoma de Madrid, 28049, Spain

Daniel Sánchez-deAlcázar and Dr. Aitziber L. Cortajarena

CIC biomaGUNE, Parque Tecnológico de San Sebastián, Paseo de Miramón 182, 20014

Donostia-San Sebastián, Spain

Dr. Pedro. B. Coto

Department of Physical and Analytical Chemistry, University of Oviedo, Avda. Julián

Clavería 8, 33006 Oviedo, Spain.

[**] V.F-L. and R.D.C. acknowledge the program "Ayudas para la atracción de talento investigador - Modalidad 1, of the Consejería de Educación, Juventud y Deporte - Comunidad de Madrid with reference number 2016-T1/IND-1463". R. D. C. acknowledges the Ramón y Cajal program (RYC-2016-20891), the Europa Excelencia program (ERC2018-092825) from the Spanish MINECO, the 2018 Leonardo Grant for Researchers and Cultural Creators from BBVA Foundation, and the FOTOART-CM project funded by Madrid region under programme P2018/NMT-4367". P.B.C. acknowledges financial support from the Regional Council for Industry and Employment of the Principality of Asturias, and the European Regional Development Fund (ERDF). A.L.C. acknowledges the European Research Council ERC-CoG648071-ProNANO, the Spanish Ministry of Economy and Competitiveness (BIO2016-77367R), the Basque Government (Elkartek KK-2017/00008). This work was performed under the Maria de Maeztu Units of Excellence Program from the Spanish State Research Agency - Grant No. MDM-2017-0720 (CIC biomaGUNE).

Supporting Information is available online from Wiley InterScience or from the authors.

Keywords: Fluorescent proteins - Color down-converting filters• Thermal- and photodeactivation mechanisms $\bullet$ Hybrid light-emitting diodes $\bullet$ Bio-hybrid light-emitting diodes

Abstract: Color down-converting filters with fluorescent proteins (FPs) embedded in a polymer matrix have led to new bio-hybrid light-emitting diodes (Bio-HLEDs), featuring stabilities of $100 \mathrm{~h}$ and $<1 \mathrm{~min}$ at low and high applied currents, respectively. Herein, we decipher the FP deactivation mechanism in Bio-HLEDs at high driving currents. Primary, the non-radiative vibrational energy relaxation of FPs promotes the release of the excess of energy to the polymer matrix, reaching $60^{\circ} \mathrm{C}$ and, in turn, a significant thermal emission quenching. 


\section{Submitted to}

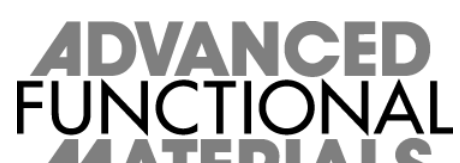

This is circumvented changing the device architecture, achieving stabilities $>300 \mathrm{~h}$ at high driving currents. Here, the photo-induced deactivation mechanism takes place, consisting of a slow and reversible partial dehydration followed by a quick and irreversible deactivation of the high-emissive ionic form. This is supported by steady-state/time-resolved emission, circular dichroism, and electrochemical impedance spectroscopic techniques. Overall, we highlight the limitations of Bio-HLEDs concerning matrix, buffers, device design, and FP stability as key aspects to achieve efficient and stable devices.

\section{Introduction}

Solid-state lighting (SSL) technologies, such as inorganic and organic light-emitting diodes (ILEDs and OLEDs, respectively), have achieved outstanding performances, including high efficiency, stability, and brightness levels. After the success attained in the development of these fundamental characteristics, sustainability and health issues are the next key aspects that have to be addressed for the development of the next generation of SSL devices. ${ }^{[1-4]}$ For example, ILEDs rely on color down-converting filters or inorganic phosphors (IPs) based on non-abundant rare-earth materials and/or toxic cadmium quantum dots, implying lack of sustainability and high environmental impact related to mining, refining, transport, and recycling of toxic elements. ${ }^{[5-7]}$ As far as health issues are concerned, long time exposition to the strong blue component of white-emitting ILEDs has been ascribed to undesired visual and non-visual effects in humans, such as irreversible damage of the eye photoreceptors in children $(<10$ years old) and changes of the brain chemistry in adults affecting the circadian rhythm, among others. ${ }^{[8-}$ ${ }^{13]}$ For these reasons, there is a renewed interest in developing new eco-friendly and sustainable SSL approaches. ${ }^{[7,9]}$

A leading example in this respect is the hybrid light-emitting diode (HLED) technology, which has experienced a renaissance over the last years. HLEDs aim to replace IPs with lowprice, highly luminescent organic molecules as color down-converting packaging or organic 
Submitted to

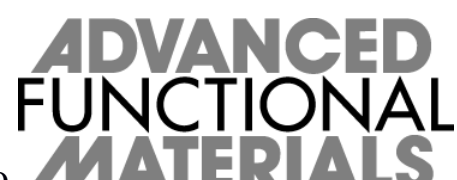

phosphors (OPs) without losing the high efficiency and brightness of ILEDs. Up to date, a myriad of OPs based on polymers, carbon quantum dots, coordination complexes, laser dyes, transition metal complexes, pure organic biomarkers, and fluorescent proteins (FPs) are under development. ${ }^{[14-27]}$ While excellent color characteristics (color rendering index (CRI) superior to 90 and efficiencies over $100 \mathrm{~lm} / \mathrm{W}$ ) have been achieved, ${ }^{[23,28]}$ their low stability is still a major drawback. ${ }^{[7]}$ Nevertheless encouraging breakthroughs have recently been reported with FPs showing stabilities of $300 \mathrm{~h},{ }^{[29]}$ perylene diimides $c a .500 \mathrm{~h},{ }^{[30]} \mathrm{Ir}(\mathrm{III})$ coordination complexes, and hybrid luminescent silica nanoparticles $>1000$ h. ${ }^{[28,31]}$ In addition, the combination of yellow- and orange-emitting $\operatorname{Ir}(\mathrm{III})$ complexes has led to remarkable efficiencies of up to $100 \mathrm{~lm} / \mathrm{W}$ operating under ambient conditions without using other protective layers. ${ }^{[28,31]}$ However, these color filters require a multilayered architecture, in which a bottom-up energy transfer allows to modulate the color response. This was circumvented implementing organo-metallic dots based on a mixture of blue-, green-, and red-emitting $\operatorname{Ir}(\mathrm{III})$ complexes as a core that is further shielded by a mesoporous silica shell. This resulted in whiteemitting organometallo-silica nanoparticles that led to sun-light HLEDs with remarkable extrapolated stabilities of $>10000 \mathrm{~h}^{[28,31]}$

Among these systems, FPs are, however, considered a paradigm of sustainability in HLEDs due to i) their distinctive ecological features, such as unlimited low-cost production using bacteria, fully recyclable nature, and easy design with genetically encoded mutations, ii) excellent luminescent features, such as narrow emission bands spanning the whole visible range, high photoluminescence quantum yields $(\phi)$, good photostability, and a high photon flux saturation, ${ }^{[32]}$ and iii) easy device implementation features, such as the possibility of direct use after extraction from bacteria without the need of purification, ${ }^{[19]}$ and stability over years in a polymer matrix under ambient storage conditions. ${ }^{[18,21,28]}$ All these features make FP-based OPs a frontrunner approach to advance HLEDs. 


\section{Submitted to}

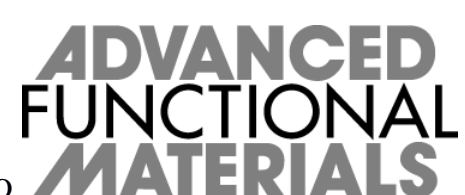

The first Bio-HLEDs featured a color down-converting packaging based on a mixture of branched and linear polyethylene oxides with FPs, achieving device stabilities of $100 \mathrm{~h}$ with luminous efficiency of $50 \mathrm{~lm} / \mathrm{W}$ at low applied currents. ${ }^{[21]}$ Here, the key aspect is the FPpolymer interaction that keeps the FP emission over years as well as the need of using a millimeter thick color down-converting coating featuring a bottom-up energy transfer process, in which blue-LED is partially converted to green light (coating with enhanced green fluorescent protein or eGFP) and this one to red with a top coating with mCherry FP. The versatility of this approach also allows for the use of 3D printing to fabricate thin $(300 \mu \mathrm{m})$ micropatterned FP-based filters for display applications, ${ }^{[18]}$ and more recently, newly engineered white FPs have been applied to a very thin $(100 \mu \mathrm{m})$ single-layered Bio-HLEDs featuring enhanced stabilities $(300 \mathrm{~h})$ and color quality $(\mathrm{CRI}>90) .{ }^{[31]}$ In parallel, other groups have demonstrated the use of FPs as color converters in bio-lasers, achieving the best performing organic-based lasers to date. ${ }^{[33-40]}$ Noteworthy, other examples of protein-based OPs have recently been reported, showing great device performance upon encapsulating coordination complexes, laser dyes, and luminescent polymers in biological matrices, such as mucin, ${ }^{[41,42]}$ starch, ${ }^{[43]}$ cellulose,${ }^{[22,44]}$ silk fibroin, ${ }^{[45-47]}$ R-phycoerythrin proteins, ${ }^{[48]}$ and DNA. ${ }^{[49]}$

These early works have clearly stated the great potential of using FP-polymer coatings as color down-converting filters in Bio-HLEDs. However, future advances require a solid understanding of the deactivation mechanisms of FPs in the polymer network under device operating conditions. This is even more critical for devices driven at high applied currents, since the stability dramatically reduces to just a few minutes - vide infra.

In biology, temperature- and photo-induced denaturation/renaturation of FPs in solution has been well-established using different buffers and additives. For instance, photobleaching, blinking, irreversible loss of fluorescence, and maximum wavelength emission shifts have been 
Submitted to

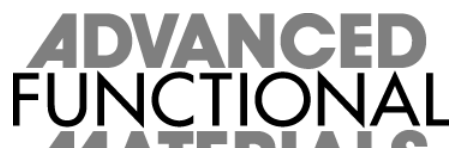

attributed to changes of the chromophore nature, ${ }^{[50-53]}$ decarboxylation processes, ${ }^{[54,55]}$ oxidative processes, ${ }^{[56]}$ reversible photochromism, ${ }^{[57,58]}$ etc. Most of the aforementioned deals with the characteristic behavior of the archetypal eGFP in physiological conditions or in aqueous solution. But there is a lack of this type of studies in polymer matrices, in general, and in those suited for color down-converting packaging in HLEDs, in particular.

This fact constitutes the main motivation of this work, in which we unravel the origin of both thermal- and photo-deactivation mechanisms of FP-OPs based on the archetypal eGFP in Bio-HLEDs operating at high driving currents. On one hand, we ascribe the heat generation of the FP-coating to vibrational and rotational modes of FPs, which upon continuous excitation, transfer this energy to the polymer surrounding environment until reaching a maximum temperature related to polymer network melting temperature. In addition, over excitation of the FPs due to light-trapping effects in agglomerates cannot be ruled out. On the other hand, we circumvent the temperature deactivation changing the device architecture, increasing the stability from $<1 \mathrm{~min}$ to $\mathrm{ca} .300 \mathrm{~h}$. Here, a purely photo-induced deactivation consisting of a slow and reversible dehydration process followed by a quick and irreversible deactivation of the ionic form of the chromophore. This effect is attributed to structural or dynamic changes in the local environment of the chromophore that modifies the overall charge distribution of the chromophore cavity, as supported by steady-state/time-resolved emission, circular dichroism (CD), and electrochemical impedance spectroscopic (EIS) techniques. Interestingly, the photoinduced deactivation mechanism is highly dependent on the type of buffer. Surprisingly, the best performing Bio-HLEDs are obtained using buffer-free FP-polymer coatings, while standard buffers lead to device stabilities $<20 \mathrm{~h}$. Hence, this work highlights the limitations of the FP-polymer stabilization and its use in Bio-HLEDs with respect to temperature- and photoinduced deactivation processes, providing information that allows us to obtain enhanced device stabilities up to hundreds of hours (>300 h). 


\section{Results and Discussion}

Submitted to

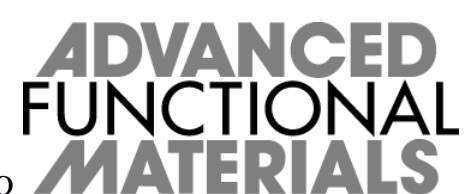

\subsection{Insights into the degradation of the Bio-HLEDs}

Prototypical Bio-HLEDs consist of a blue-emitting LED $(450 \mathrm{~nm})$, in which the packaging is replaced by the FP-coating. This is prepared by adding a branched polyethylene oxide to a buffer-free solution of eGFP under stirring conditions, resulting in a hydrogel mixture. The latter is transformed into an elastomeric material by adding a linear polyethylene oxide and applying a gentle vacuum from 200 to 3 mbar in a $4 \mathrm{~h}$ time span - see experimental section for details. The device characterization consists in monitoring the changes of the FPcoating emission or conversion emission band with respect to intensity ( $t_{50 \%}$ or time to reach half of the initial intensity) and color stability (shifts of $\lambda_{\max }$ or the maximum emission wavelength), as well as the temperature of the coating at constant applied currents. ${ }^{[21]}$

a)

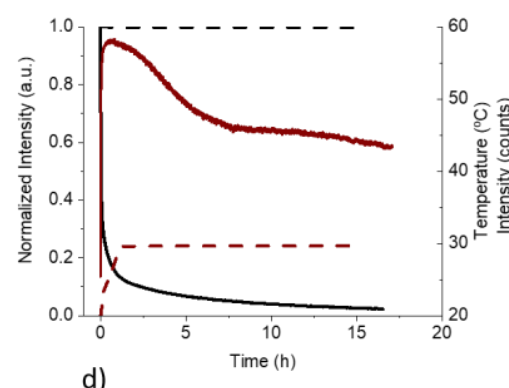

d)

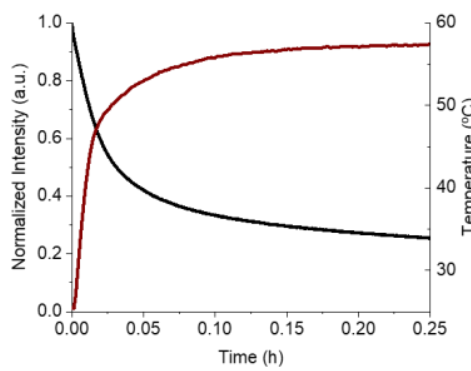

b)

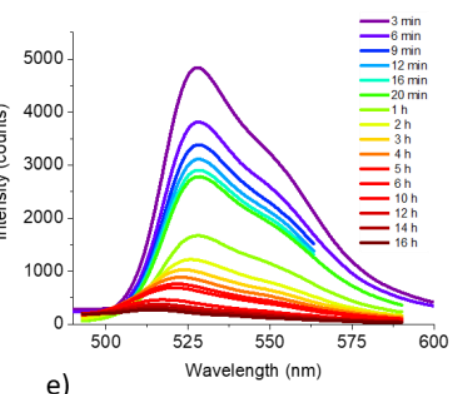

e)

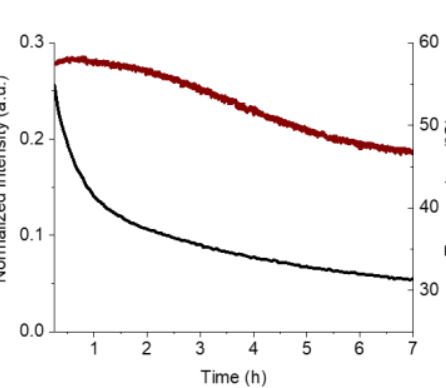

c)

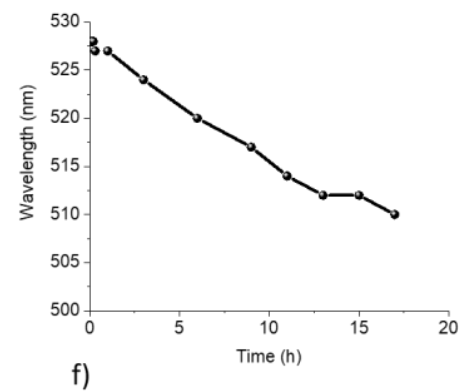

f)

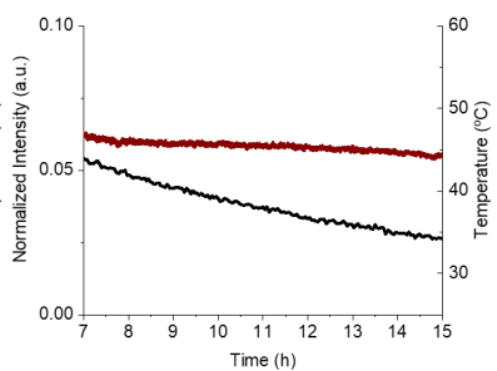

Figure 1. Typical performance of Bio-HLEDs operating at high applied currents (200 mA). a) Direct comparison of the emission intensity decay (black) and increase of temperature (red) of devices with FP-coating (solid) and FP-free coating (dashed). b-c) Changes of the emission 
Submitted to

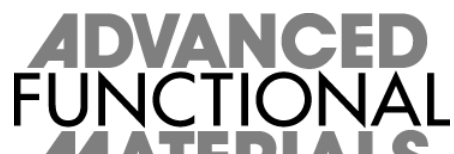

spectra (b) and $\lambda_{\max }$ (c) of the FP-coating over time. d-f) Emission intensity and temperature changes of Bio-HLEDs over time.

As an example, Figure S1 shows the typical decrease of the device efficiency upon increasing the applied current. This is related to both the charge carrier recombination loss of the chip and the increase in the temperature of the coating reaching a plateau at around $60^{\circ} \mathrm{C}$ operating at high applied currents. Figures 1a,b show the typical Bio-HLED behavior at high driving currents $(200 \mathrm{~mA})$. The Bio-HLED stability $\left(t_{50 \%}\right)$ is around $1 \mathrm{~min}$, while the temperature of the coating reaches a maximum value close to $60^{\circ} \mathrm{C}$ (Figures 1a, d). The sharp initial decrease of the FP-coating emission intensity without affecting the emission band shape $\left(\lambda_{\max }=528 \mathrm{~nm}\right)$ goes hand-in-hand with the increase of the coating temperature, leading to an efficient thermal emission quenching. In the second stage (Figure 1c, e), the intensity of the conversion band exponentially decreases showing a linear blue shift in $\lambda_{\max }(521 \mathrm{~nm}$; Figure 1d). This is associated to a decrease in the coating temperature down to $c a .45^{\circ} \mathrm{C}$ (Figure $1 \mathrm{e}$ ). Both processes point out to changes in the nature of the FP chromophore, absorbing less efficiently at the region of the LED emission and becoming less emissive. At the final stage (Figure 1c, f), the temperature of the FP-coating holds constant, while the emission intensity linearly decreases along with a further blue-shift in $\lambda_{\max }(515 \mathrm{~nm}$; Figure 1c).

To better understand the origin of the temperature increase, we study the same device with a FP-free coating (Figure 1a). Here, the blue-emitting chip reaches temperatures below $30^{\circ} \mathrm{C}$, while the temperature of the FP-free coating did not increase beyond this value. In addition, the FP-free coating does not show any absorption features in the visible region, indicating a lack of reabsorption events of both LED and FP emissions by the polymer matrix. Thus, the heat generation in Bio-HLEDs might be connected to a motion (vibrational or rotational $)^{[59-63]}$ of FPs upon continuous excitation; thought light-trapping effects related to the 


\section{Submitted to}

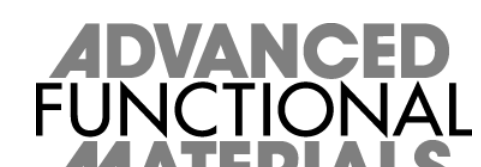

formation of protein clusters, in which FPs are over excited, cannot be ruled out. This mechanism observed in living organisms like corals is still under debate. ${ }^{[64]}$

Interestingly, differential scanning calorimetry (DSC) experiments carried out for the polymer mixture show a melting temperature of $\sim 60^{\circ} \mathrm{C}$ and a crystallization temperature of $\sim 50^{\circ} \mathrm{C}$, as well as glass transition temperature at around $-65^{\circ} \mathrm{C}$ (Figure $\mathrm{S} 2$ ). Thus, the mixture features the typical behavior of both the crystalline phase from the PEO and the amorphous phase of TMPE. Here, the crystalline region of PEO observed by melting peaks in DSC ( $55^{\circ} \mathrm{C}$ ) acts as jellifying agent that transforms the hydrogel into an elastomeric material after dehydration under vacuum. The amorphous phase coming from the mixture TMPE:PEO is mostly enriched in TMPE, since there is a neglectable temperature shift between the mixture and pristine TMPE. In this amorphous TMPE region, the FP is embedded, as it tends to interact with the aqueous regions due to its hydrophilic character. Thus, the FP surrounding might be considered as a viscous media, in which the motion of FPs is possible. The XRD assays also confirmed the presence of a crystalline phase with two well-defined peaks corresponding to the PEO and another amorphous region mainly from the TMPE (Figure S2).

Importantly, the melting temperature of the FP-coating is in line with the device operation temperatures reached upon increasing the applied current (Figures 1 and S1). In other words, FP acts as a hot spot upon excitation, melting the surrounding polymer matrix, which can still be considered as an elastomeric material. Noteworthy, the FP-polymer interaction is instrumental for the long-term stability of the FPs. Therefore, the changes in both intensity and band shape of the FP-coating beyond the temperature-induced quenching (second and third stages) are attributed to a partial denaturation of the protein backbone and/or changes in the molecular structure or electronic state of the chromophore, since the FPs are embedded in a quasi-melted phase in the matrix network. This includes i) small conformational changes of the $\beta$-barrel induced by dehydration processes, ii) changes in the nature of the emitting excited state 
Submitted to
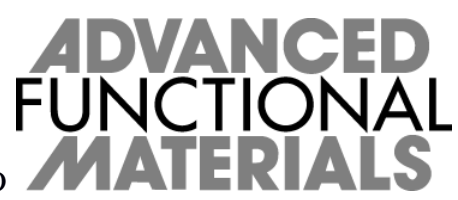

via excited state proton transfer (i.e., neutral, anionic, and intermediate forms), and iii) deactivation via, for example, triplets, cis/trans isomerization, etc. ${ }^{[65-67]}$ Other emission deactivation mechanisms, such as photooxidative reddening and reversible photochromism are excluded, since the final emission should be red-shifted. ${ }^{[56-58]}$

Overall, the FP-coating emission deactivation upon irradiation and temperature stress is related to the weakening of the FP-polymer interaction in the quasi-melted state, leading to changes in the structure of the chromophore and/or the partial distortion of the $\beta$-barrel. Thus, it is instrumental to decouple both processes to shed light onto the limiting factors towards longliving Bio-HLEDs driven at high applied currents - see sections 2.2 and 2.3.

\subsection{Insights into the origin of the temperature-induced emission deactivation mechanism}

Fresh FP-coatings were placed on a heating station increasing its temperature from $25^{\circ} \mathrm{C}$ to $100^{\circ} \mathrm{C}\left(2^{\circ} \mathrm{C} / \mathrm{min}\right)$, while monitoring the emission intensity of the eGFP (Figure 2 ).
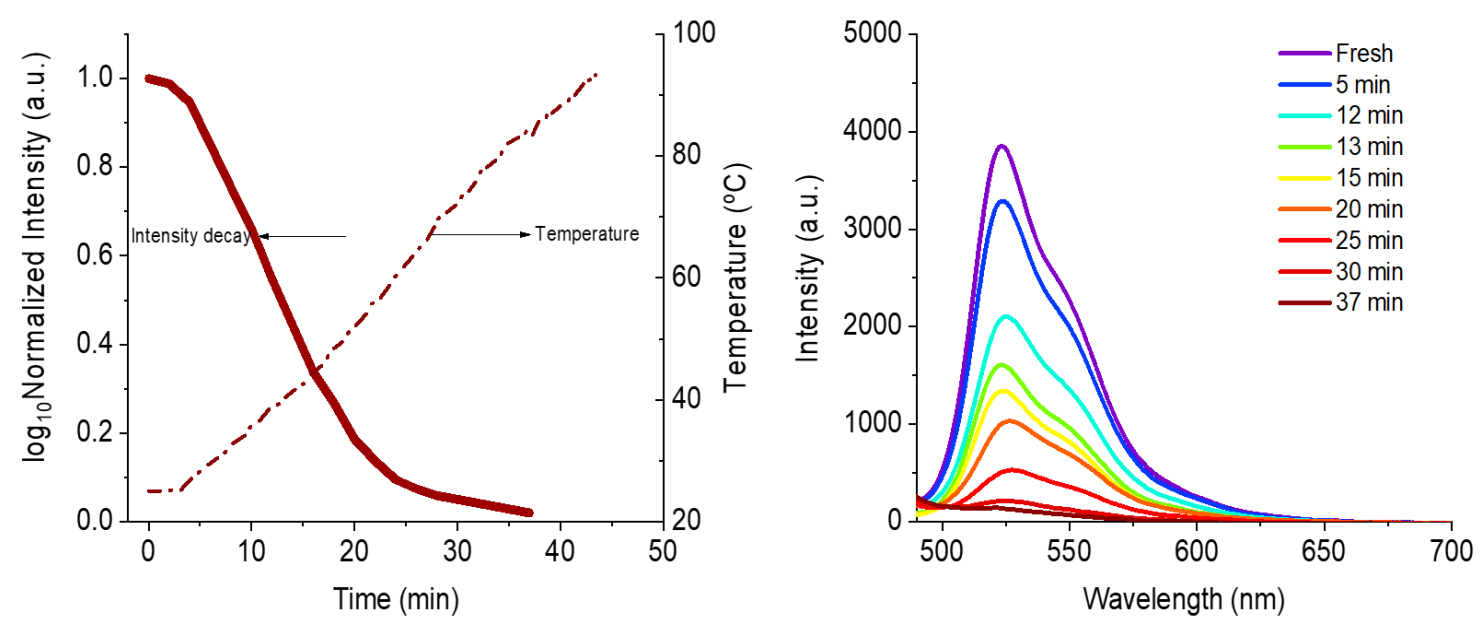

Figure 2. Thermal behavior of buffer-free FP-coatings with respect to changes of the eGFP emission intensity (left) and emission band shape (right) upon increasing temperature of the FP-coating over time $\left(2^{\circ} \mathrm{C} / \mathrm{min}\right)$. 
Submitted to

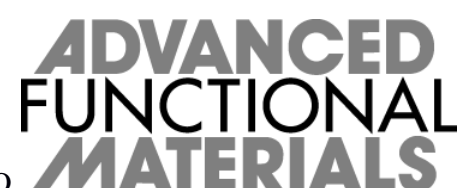

Typically, the emission of the eGFP holds constant up to the melting temperature $\left(T_{\mathrm{m}}\right.$ or $50 \%$ emission loss) of around $70^{\circ} \mathrm{C}$ in solution. ${ }^{[68-70]}$ In contrast, $T_{\mathrm{m}}$ is significantly reduced $\left(45^{\circ} \mathrm{C}\right)$ in the polymer matrix, without noting any change in the emission band shape (Figure 2). We assign this finding to the beginning of the melting process of the polymer matrix, which reduces the FP-polymer interaction and, in turn, the FP stability. This prompted us to study the thermal stability of the FP in the elastomeric matrix at the onset of the melting process (i.e., $50^{\circ} \mathrm{C}$ ). In addition, the possible emission recovery after cooling down the system to room temperature was also analyzed (Figure 3).
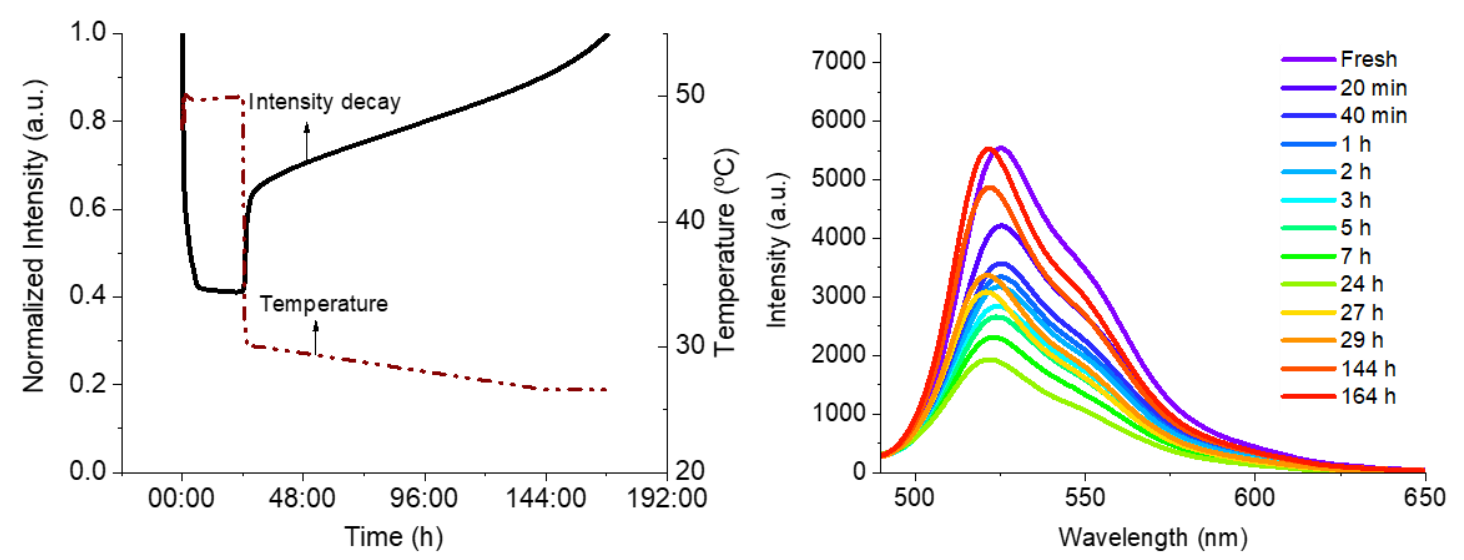

Figure 3. Thermal stability of buffer-free FP-coatings at a constant temperature $\left(50{ }^{\circ} \mathrm{C}\right)$ for 24 $\mathrm{h}$ and after cooling, monitoring the emission intensity (left) and emission band shape (right) upon excitation with a blue LED $(440 \mathrm{~nm})$ for $5 \mathrm{~s}$ every $10 \mathrm{~min}$. Please note that the emission intensity is not fully recovered, since the initial intensity in the isothermal study corresponds to roughly half of the emission of a fresh FP-coating at room temperature.

The isothermal studies at $50{ }^{\circ} \mathrm{C}$ showed loss of $60 \%$ in the FP-coating emission intensity during the first $7 \mathrm{~h}$, staying constant for the next $17 \mathrm{~h}$. Here, the emission band shape did not significantly change, suggesting that the nature of the emitting excited state holds. ${ }^{[71]}$ Noteworthy, this data is in perfect agreement with the behavior of Bio-HLEDs, in which the 


\section{Submitted to

second stage involves an exponential decay of emission that occurred for a similar period of

time (Figure 1e). However, a continuous decrease of the emission intensity along with a blue shift in $\lambda_{\max }$ from $527 \mathrm{~nm}$ to $517 \mathrm{~nm}$ was noted in Bio-HLEDs (Figure 1c), in which both temperature and photo stress are operative.

After $24 \mathrm{~h}$, we proceeded to study the self-regeneration process at room temperature in the dark, monitoring the recovery of emission intensity over time. The main characteristics of the original emission at $50^{\circ} \mathrm{C}$ were recovered after $150 \mathrm{~h}$, maintaining the emission band shape except for a slightly blue-shifted $\lambda_{\max }$ (Figure 3), but the emission intensity was not fully recovered compared to that of a fresh FP-coating at room temperature, since the initial intensity in the isothermal study corresponds to roughly half of the emission of a fresh FP-coating (Figure 2).

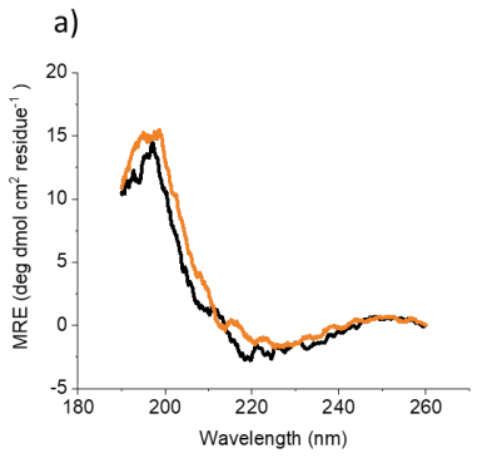

b)

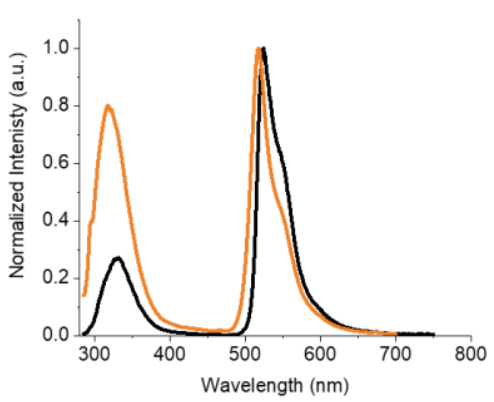

c)

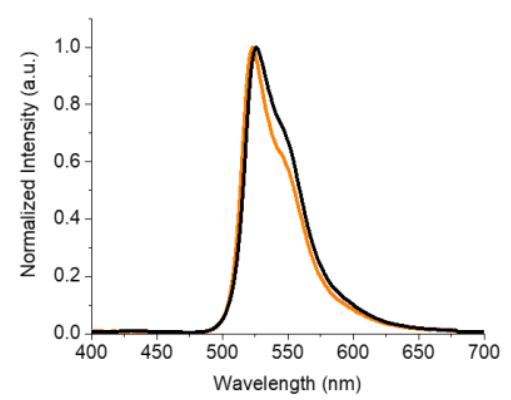

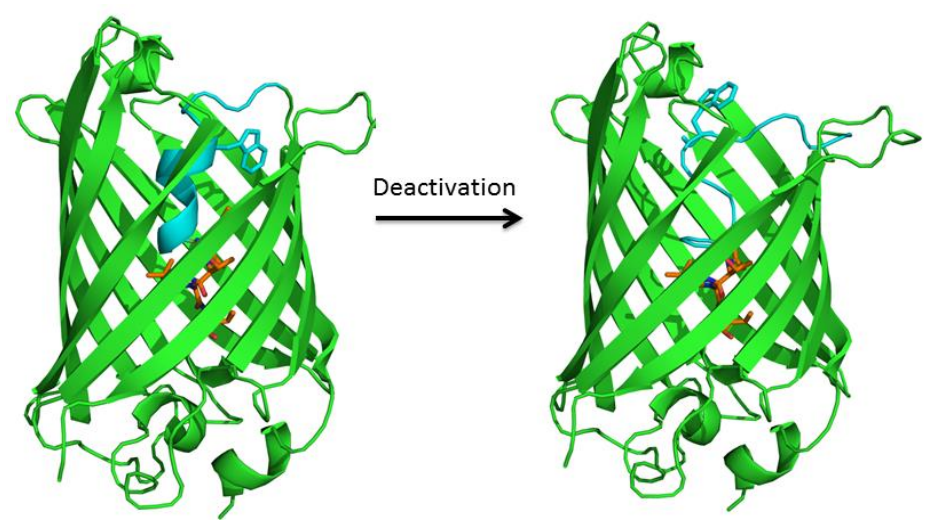

Figure 4. Top: Circular dichroism spectrum (a) and emission spectra at excitation wavelength of $275 \mathrm{~nm}$ (b) and $375 \mathrm{~nm}$ (c) of fresh (black) and heated (orange) FP-coatings. Bottom: Schematic representation of the partial conformational change reducing the Trp57- 


\section{Submitted to

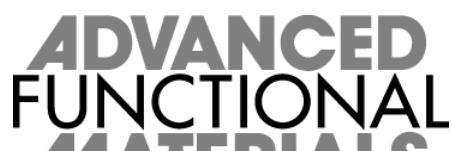

chromophore FRET mechanism. The crystal structure of eGFP (PDB ID: 2Y0G) featuring the chromophore as orange sticks, the Trp57 as cyan sticks, and the inner helix and interconnection loop as cyan ribbons is shown.

To shed light onto this aspect, we carried out spectroscopic studies with CD, steadystate and time-resolved emission, and EIS of both fresh and heated FP-coatings (Figures 4 and S4). Firstly, CD measurements showed spectra predominantly dominated by the characteristic signal of a $\beta$-sheet secondary structure after $24 \mathrm{~h}$ at $50^{\circ} \mathrm{C}$, discarding the total unfolding of the protein. Nevertheless, the protein might adopt a distorted conformation, namely a partial loss of tertiary structure or simply a more relaxed and dynamic conformation. However, both the $\phi$ and the excited state lifetimes $(\tau)$ are strongly reduced from $70 \%$ to $30 \%$ and from 2.02 ns to $1.81 \mathrm{~ns}$ for fresh and heated FP-coatings, respectively. Excitation at $375 \mathrm{~nm}$ revealed the band shape of the ionic chromophore $\left(\lambda_{\max }=528 \mathrm{~nm}\right)$ with no presence of the neutral form $\left(\lambda_{\max }=450\right.$ $\mathrm{nm})$, discarding a change in the protonation state of the chromophore. However, excitation at $275 \mathrm{~nm}$ leads to a new emission band centered at $320 \mathrm{~nm}$, corresponding to the intrinsic protein fluorescence, that is very useful to evaluate the denaturation degree of eGFP. In detail, the highenergy band can be related to both tyrosine (Tyr) and tryptophan (Trp57) aromatic residues. However, the Tyr emission is quenched by its interaction with the peptide chain that has not changed as suggested by CD assays. ${ }^{[72-74]}$ Therefore, the change of the emission is typically related to a conformation change of the Trp57 surroundings. In detail, Trp57 is located at the end of the inner helix and at the beginning of an interconnection loop at $13 \AA$ to $15 \AA$ away from the chromophore, and its emission is quenched by an efficient Förster resonance energy transfer (FRET) process to both neutral and ionic forms of the FP chromophore. ${ }^{[75]}$ If a partial conformational change of the $\beta$-barrel takes place, the local environment around the chromophore changes, hindering the Trp57-chromophore FRET mechanism. The intensity ratio 
Submitted to

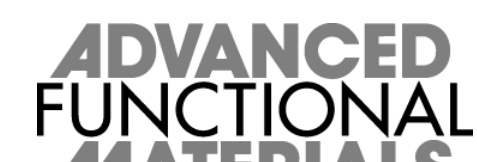

between Trp57 and the chromophore emissions is typically used to study the partial denaturation of FPs. ${ }^{[74]}$ This ratio increases from $\sim 0.26$ (fresh FP-coating) to $\sim 0.80$ (heated FPcoating), confirming that the FP structure is partially denatured upon heating, slightly changing the environment of the ionic form of the chromophore. Finally, the Trp57 maximum emission wavelength is centered at $\sim 320 \mathrm{~nm}$, indicating that it is embedded in a non-polar environment alike to that of the polymer matrix.

As noted in the literature, ${ }^{[60]}$ a partial denaturation could be related to a change in the hydrogen-bonded water networks surrounding the protein, leading to a conformational change of the Trp57 environment, in particular, and of the $\beta$-barrel, in general. To confirm this, the heated FP-coatings were rehydrated - see experimental section for details. Interestingly, a total recovery of the spectroscopic properties with respect to Trp57-chromophore ratio $(0.27), \phi$ ( 70\%), and $\tau(2.1 \mathrm{~ns})$ was noted (Figure S3 and Table 1). Finally, the EIS characterization was performed. The Nyquist plots and the circuit model for the fitting are shown in Figure $\mathbf{S 4}$. Typically, the Nyquist plots consist of two features, namely i) a high frequency semicircle, which is characteristic of the ionic bulk conductivity of the sample $\left(R_{\mathrm{p}}\right)$ and ii) a linear region at the low frequency regime, which is connected to the polarization resistance at the electrode interfaces $(R) .{ }^{[76]}$ In short, taking a FP-free coating as a reference, the presence of FPs in the matrix leads to a reduced $R_{\mathrm{p}}$ and an increased dielectric constant $(\varepsilon)$. This suggests an increase of the bulk conductivity, since FPs assist water organization and movements across the protein skeleton. In contrast, heated FP-coatings show a significant increase of $R_{\mathrm{p}}$ and a reduction of $\varepsilon$, confirming that a severe denaturation of the FP is not taking place. ${ }^{[76]}$

All the aforementioned indicates that the temperature-induced emission quenching in the FP-coating is controlled by the thermal properties of the polymer matrix, while its deactivation mechanism involves a dehydration process that is fully reversible.

\subsection{Insights into the origin of the photo-induced emission deactivation mechanism}


Submitted to

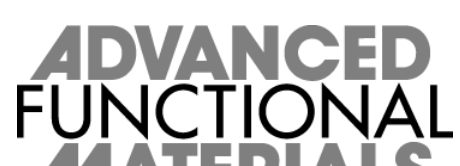

To prevent the increase in temperature of the FP-coating at high applied currents, we turn to use a remote device architecture, in which the FP-coatings are placed at different distances $(0.5,1$, and $2 \mathrm{~cm})$, reducing the incident photon flux density and, in turn, the temperature - Figure S5. For instance, Bio-HLEDs with FP-coatings placed 'on chip' reached a maximum temperature of $c a .60^{\circ} \mathrm{C}$ in 10 minutes, while remote Bio-HLEDs $(0.5,1$, and 2 $\mathrm{cm}$ ) reached a maximum temperature of 40,33 , and $27^{\circ} \mathrm{C}$ in 12,20 , and 30 minutes, respectively. Thus, the remote set-up $\left(\lambda_{\mathrm{exc}}=450 \mathrm{~nm}\right)$ allowed us to monitor the photo-induced changes of the FP-coating emission at controlled temperatures over time.

Similar to the 'on chip' devices, the emission decay of the remote Bio-HLEDs $(0.5$ and $1 \mathrm{~cm}$, Figures 5 and S6, respectively) evolved showing three well-defined regimes over time. In the first stage, the FP-coating emission was thermally quenched (40\% and $10 \%$ emission intensity loss, respectively) without changing the emission band shape $\left(\lambda_{\max }=529 \mathrm{~nm}\right)$, as the FP-coating temperature reached its maximum value (Figures $\mathbf{5 c}, \mathrm{d}$ and $\mathbf{S 6} \mathbf{c}, \mathrm{d}$ ). This is followed by a second stage, in which the emission intensity slowly decays following a two-step behavior (Figures 5e and S6e). Here, the emission intensity and band shape did not change $\left(\lambda_{\max }=528\right.$ $\mathrm{nm}$ ) for approximately $15 \mathrm{~h}$ and were followed by a slow and continuous loss in intensity in concert with a blue-shift of $\lambda_{\max }(523 \mathrm{~nm})$ until reaching the second plateau after $25-35 \mathrm{~h}$ that holds constant for 15-30 h. The final stage is always an exponential decay of the FP-coating emission along with a significant blue shift of the $\lambda_{\max }(509 \mathrm{~nm}$; Figures $\mathbf{5 c}$,f and $\mathbf{S 6}$ c,f). Importantly, the emission of the irradiated FP-coatings is not reversible at room temperature upon switching off the device. 


\section{Submitted to}

a)

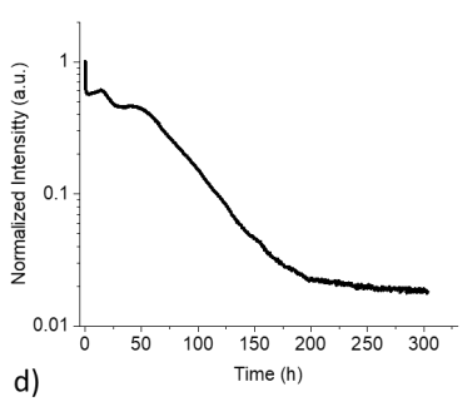

d)

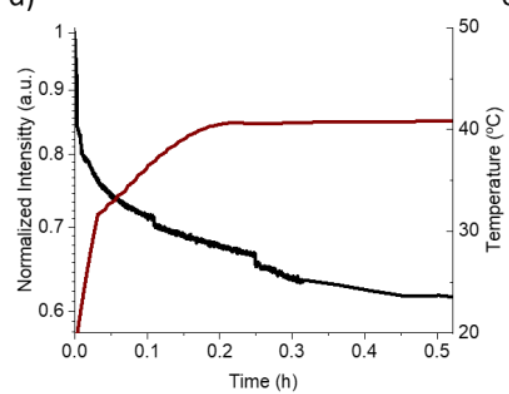

b)
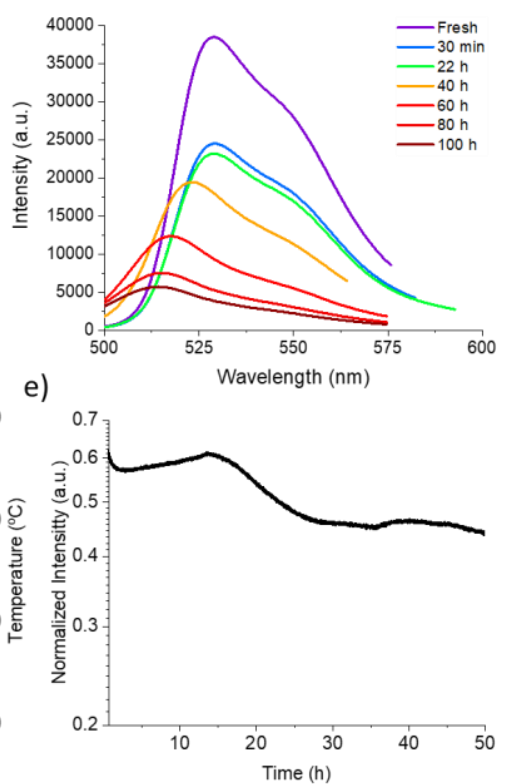

c)
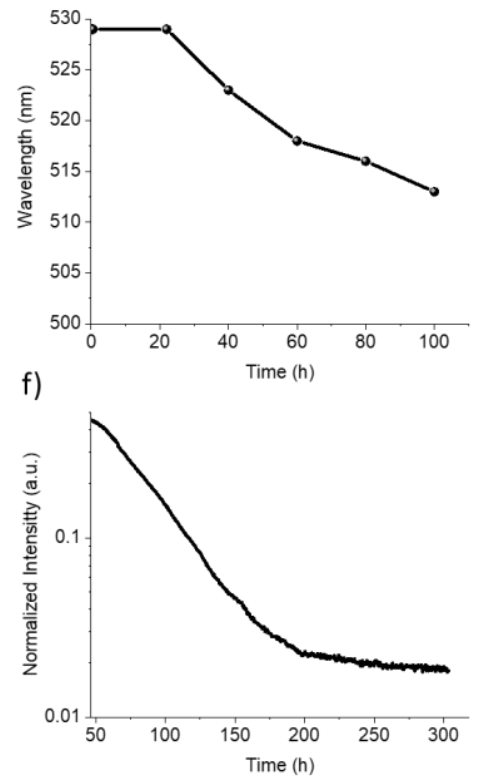

Figure 5. Typical performance of remote Bio-HLEDs $(0.5 \mathrm{~cm})$ operating at high applied currents (200 mA; $\left.\lambda_{\text {exc }} 450 \mathrm{~nm}\right)$. a) Emission intensity decay over time. b-c) Changes of the emission spectra (b) and $\lambda_{\max }$ (c) of the FP-coating over time. d-f) Emission intensity (black) and temperature (red) changes of Bio-HLEDs over time.

Except for the initial thermal quenching, a similar step-wise deactivation was noted for $2 \mathrm{~cm}$ remote Bio-HLEDs, in which the temperature was kept close to $25^{\circ} \mathrm{C}$ during the whole experiment, allowing us to study the purely photo-induced deactivation process (Figure 6). The changes in emission intensity followed a characteristic pattern. During the first $80 \mathrm{~h}$ (Figure 6a, c), the emission intensity was kept almost constant with an emission band peaking at 529 nm (Figure 6b, c). After that, a slow linear decay (20\% loss) along with a constant blue-shift of $\lambda_{\max }(524 \mathrm{~nm}$ ) until $130 \mathrm{~h}$ was noted (Figure 6d). This was followed by a plateau, which held constant for $35 \mathrm{~h}$. At around $170 \mathrm{~h}$, a second decay associated to both an intensity loss (20\%) and a shifted $\lambda_{\max }$ takes place (519 nm; Figure 6b, c, e). This led to a second plateau until 300 $\mathrm{h}$, followed by a sharp exponential decay of the emission intensity associated to a significant blue shifted emission (510 nm; Figure 6b, c, e). 
Submitted to

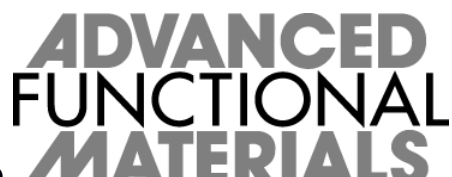

Following the previous characterization, we focused on analyzing the spectroscopic changes of the FP-coatings at the different stages of the Bio-HLED $(2 \mathrm{~cm})$ lifetime. Firstly, CD assays confirmed the presence of the $\beta$-sheet architecture of the secondary structure regardless of the thermal and irradiation stress (Figure S7), discarding the complete denaturation of the FP.
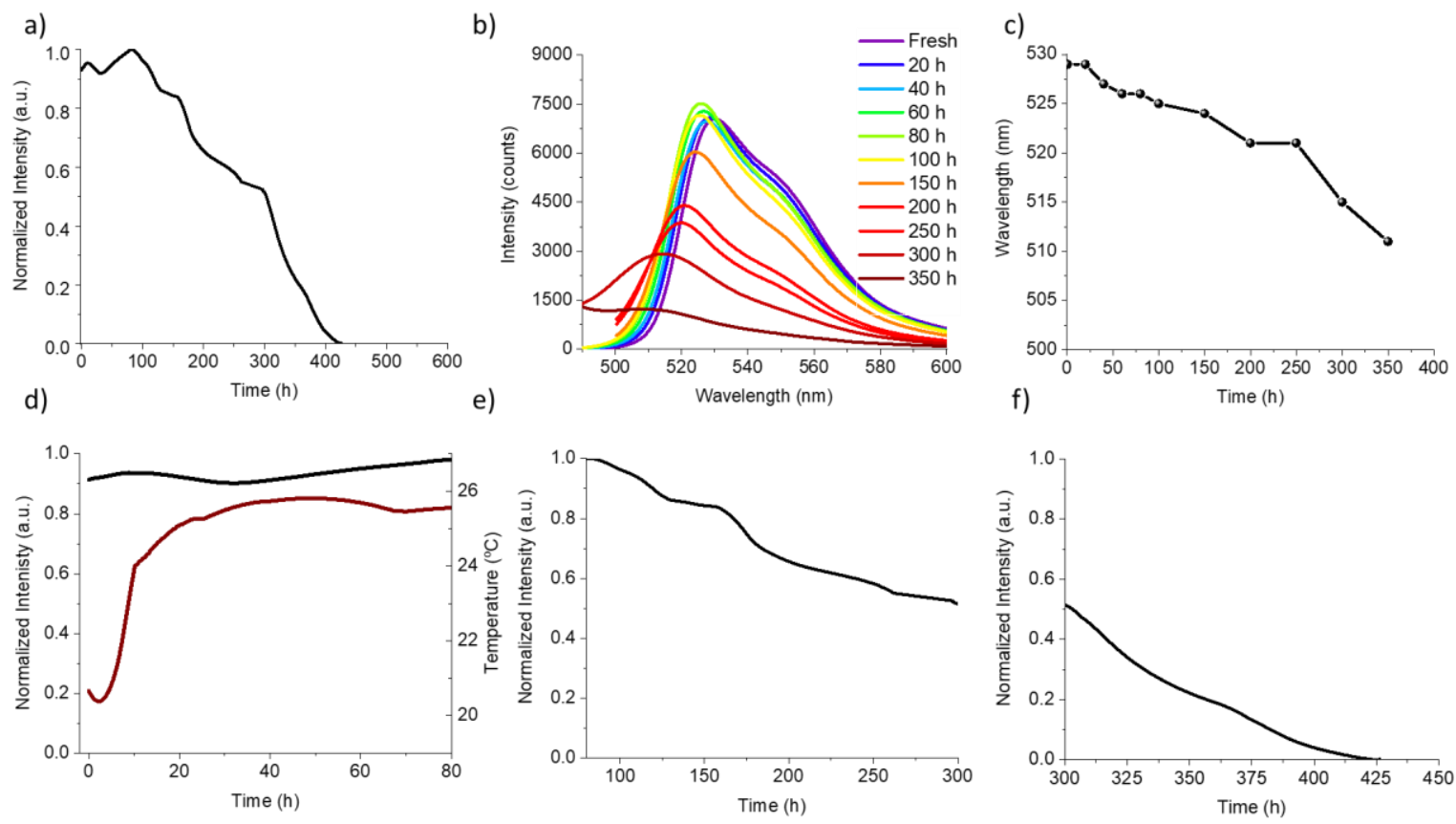

Figure 6. Typical performance of remote Bio-HLEDs $(2 \mathrm{~cm})$ operating at high applied currents (200 mA; $\lambda_{\text {exc }} 450 \mathrm{~nm}$ ). a) Emission intensity decay over time. b-c) Changes of the emission spectra (b) and $\lambda_{\max }$ (c) of the FP-coating over time. d-f) Emission intensity (black) and temperature (red) changes of Bio-HLEDs over time.

Next, we monitored the changes of the emission features using steady-state emission spectroscopy over time. The emission spectra upon excitation at 275 and $375 \mathrm{~nm}$ are shown in Figure 7, while the $\phi$ and $\tau$ are summarized in Table 1. The results show values of $\phi \sim 70$ and $\tau$ of $c a .2$ ns that do not change during the initial 80 h. However, the Trp57-chromophore ratio slightly rises up to values of 0.40 , suggesting a partial dehydration. This becomes more critical in the timeframe $144 \mathrm{~h}$ to $275 \mathrm{~h}$, in which the ratio Trp57-chromophore increased above 1 , the 
Submitted to

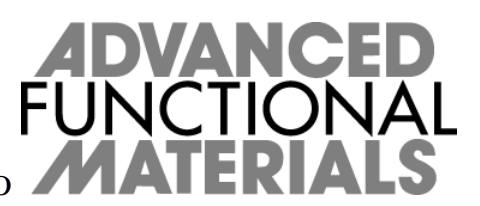

$\phi$ and $\tau$ values are significantly reduced, and a blue-shifted $\lambda_{\max }$ is noted (Table $\mathbf{1}$ and Figure

7). Contrary to temperature-induced deactivation, excitation at $375 \mathrm{~nm}$ shows a new band evolving at around $450 \mathrm{~nm}$ during this timeframe, indicating that the chromophore slowly deactivates, remaining the non-emissive neutral form of the chromophore. All these changes are more evident after $375 \mathrm{~h}$ (Table 1), since i) no significant $\phi$ is observed, ii) the emission is dominated by the neutral form of the chromophore $\left(\lambda_{\max }=450 \mathrm{~nm}\right)$, and iii) the Trp57 emission is further red-shifted (Figure 7), indicating that the aminoacid is located in a non-polar environment, such as the polymer matrix. These suggest that the photo-induced process leads to a slow dehydration of the FPs causing a structural change of the $\beta$-barrel (note the Trp57chromophore ratio) that ends up into a fully deactivation of the emitting ionic form, remaining the non-emissive neutral form.
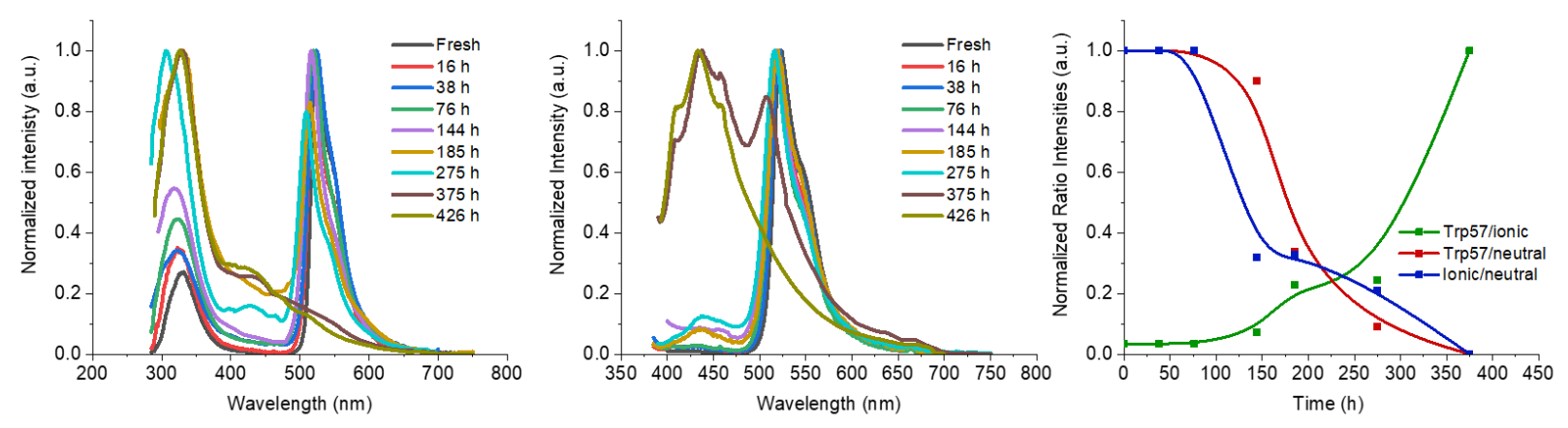

Figure 7. Emission spectra of buffer-free FP-coatings used in remote Bio-HLEDs $(2 \mathrm{~cm})$ architectures upon excitation at $275 \mathrm{~nm}$ (left) and $375 \mathrm{~nm}$ (center) as well as the normalized emission intensity ratio between the $\operatorname{Trp} 57$, the ionic, and the neutral forms at different degradation stages (right). 
Submitted to

Table 1. Relevant spectroscopic and EIS data of FP-coatings used in remote Bio-LED $(2 \mathrm{~cm})$ architectures at different degradation stages before and after rehydration.

\begin{tabular}{|c|c|c|c|c|c|c|}
\hline Sample & $\begin{array}{c}\text { Trp57- } \\
\text { chromophore } \\
\text { ratio }^{\mathrm{a}, \mathrm{b}}\end{array}$ & $\begin{array}{c}\lambda_{\max }^{\mathrm{a}, \mathrm{c}} \\
(\mathrm{nm})\end{array}$ & $\begin{array}{l}\phi^{\mathrm{a}, \mathrm{d}} \\
(\%)\end{array}$ & $\begin{array}{l}\tau^{a, e} \\
(\mathrm{~ns})\end{array}$ & $\begin{array}{c}R_{\mathrm{p}}^{\mathrm{a}, \mathrm{f}} \\
\left(10^{5} \Omega\right)\end{array}$ & $\varepsilon^{\mathrm{a}, \mathrm{f}}$ \\
\hline Fresh & 0.27 & 529 & 70 & 2.03 & 0.16 & 4.5 \\
\hline $16 \mathrm{~h}$ & $0.34 / 0.40$ & $529 / 526$ & $68 / 72$ & $1.89 / 2.04$ & $0.18 / 0.21$ & $4.7 / 4.1$ \\
\hline $38 \mathrm{~h}$ & $0.32 / 0.40$ & $529 / 525$ & 70 / 65 & $1.72 / 1.82$ & $0.20 / 0.15$ & $4.6 / 4.3$ \\
\hline $76 \mathrm{~h}$ & $0.41 / 0.39$ & $529 / 523$ & $66 / 65$ & $1.88 / 2.02$ & $0.30 / 0.17$ & $3.7 / 4.1$ \\
\hline $144 \mathrm{~h}$ & $0.56 / 0.30$ & $524 / 523$ & 38 / 67 & $1.82 / 1.82$ & $0.28 / 0.17$ & $3.3 / 3.8$ \\
\hline $185 \mathrm{~h}$ & $1.20 / 0.37$ & $\begin{array}{c}519 \& 425 \\
/ 518\end{array}$ & 42 / 45 & $2.02 / 2.08$ & $0.30 / 0.25$ & $3.5 / 3.0$ \\
\hline $275 \mathrm{~h}$ & $1.26 / 1.36$ & $\begin{array}{c}514 \& 425 \\
/ 514\end{array}$ & $23 / 24$ & $2.02 / 2.08$ & $1.7 / 0.44$ & $3.2 / 3.1$ \\
\hline $375 \mathrm{~h}$ & 4.34 / 4.1 & $\begin{array}{c}510 \& 425 \\
/ 510\end{array}$ & $<5 /$ & $1.98 / 2.02$ & $1.6 / 0.8$ & $3.1 / 3.3$ \\
\hline $426 \mathrm{~h}$ & - & $-/-$ & - & $-/-$ & $2.0 / 0.9$ & $3.0 / 3.1$ \\
\hline
\end{tabular}

Finally, EIS characterization was carried out (Figure S8). Up to $185 \mathrm{~h}$, the $R_{\mathrm{p}}$ slightly increases and $\varepsilon$ decreases compared to fresh FP-coatings, suggesting a lack of complete denaturation. However, longer irradiation times significantly increase $R_{\mathrm{p}}$ with a further 


\section{Submitted to}

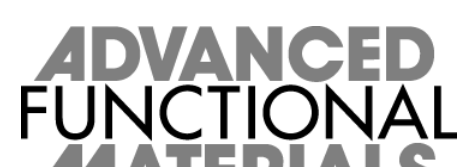

reduction of $\varepsilon$. This observation is well-correlated with spectroscopic changes towards the neutral form of the chromophore, implying a significant change in the hydrogen-bonded water networks in the protein hydration shell along with the partial denaturation of the $\beta$-barrel. It is important to notice that a complete denaturation of the FP (i.e., losing its secondary structure) should have led to lower $R_{\mathrm{p}}$ and higher $\varepsilon$ values than those of the fresh FP-coatings. ${ }^{[60]}$

All-in-all, we can postulate that the first two photo-induced deactivation steps $(<185 \mathrm{~h})$ are related to small conformational changes that assist the inside/outside $\mathrm{H}^{+}$transfer of the $\beta$ barrel changing the FP-polymer interface. This process is very slow and does not change significantly the nature of the chromophore, suggesting that it is reversible. However, this could promote a change in the FP-polymer interaction, leading to a significant deformation of the $\beta$ barrel that causes the irreversible photo-deactivation of the chromophore.

To verify this hypothesis, these samples were rehydrated and put through the same spectroscopic analysis (Figures S9). The rehydrated FP-coatings exhibited the same trend the first $185 \mathrm{~h}$, in which the ratio Trp57-chromophore, the $\phi$, and $\tau$ are recovered (Table 1). Thus, the initial deactivation steps are totally reversible. However, FP-coatings excited for more than $185 \mathrm{~h}$ did not show further change in the spectroscopic data, while a more intense emission from the neutral form of the chromophore was noted. Therefore, an irreversible step involves a major change of the protein structure leading to a change of the chromophore nature. Finally, EIS of the rehydrated FP-coatings show that hydration of shortly excited samples leads to a reduction of $R_{\mathrm{p}}$ and an increase of $\varepsilon$, while the longer excited samples exhibited similar values (Figure S10 and Table 1). This further confirms that upon long light exposure, the conformational changes of the protein are irreversible.

\subsection{Insights into the effect of conventional buffers}

A standard way to stabilize the ionic form of the FP chromophores is the use of buffer solutions of different $\mathrm{pH}$ and ionic strength values. The most used show a great buffer capacity 
Submitted to

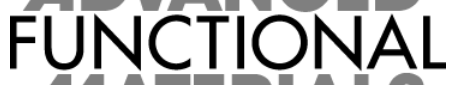

in the basic physiological range ( $\mathrm{pH} 7-8)$, such as phosphate and Tris solutions. Indeed, studies on protein denaturation and regeneration in the presence of chemical denaturants, have demonstrated that the optimum structural stability of the eGFP is found at a $\mathrm{pH}$ range of 7-8.5 using phosphate-based buffers. ${ }^{[77]}$ Regarding the conformational stability of FPs at high temperature, it was reported that phosphate buffers ( $\mathrm{pH} 7-8)$ show the best performance up to $85^{\circ} \mathrm{C} .{ }^{[7]}$ Noteworthy, all the results reported in this manuscript have been obtained using buffer-free aqueous solutions. Therefore, it is worth determining the impact of the buffer on the stability of the FP-coating. Thus, FP-coatings with the same composition were prepared using $50 \mathrm{mM}$ of sodium phosphate $\mathrm{pH} 8$ - see experimental section for details. As shown in Figure $\mathrm{S} 2$, the presence of buffer has no effect on the morphology of the FP-coating upon drying. While XRD shows the lack of formation of salt crystals, DSC shows neglectable changes corresponding to both glass transition and melting temperatures of TMPE and PEO, respectively.
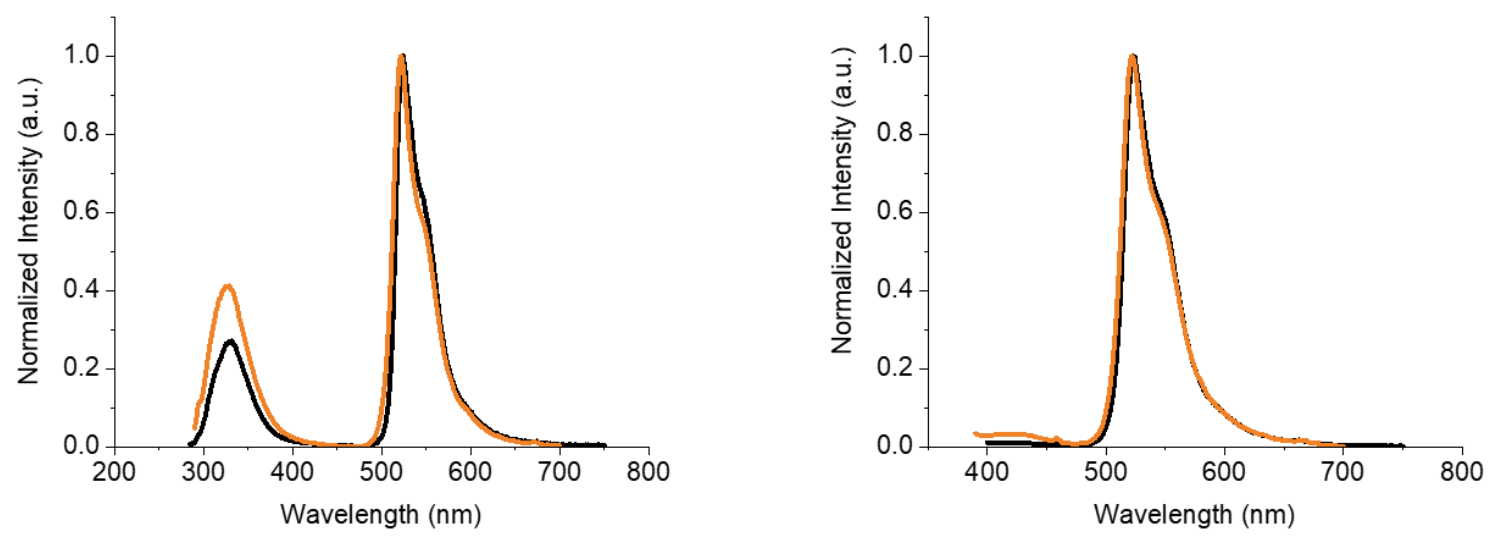

Figure 8. Emission spectra of buffer-free (black) and buffer-based (orange) FP-coatings upon excitation at $275 \mathrm{~nm}$ (left) and $375 \mathrm{~nm}$ (right).

Next, the photophysical features of the buffer FP-coating were studied (Figure 8). The buffer-based FP-coatings showed similar emission features as the reference buffer-free FP- 


\section{Submitted to}

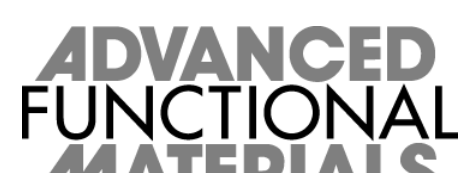

coatings, that is, $\lambda_{\max }$ of $523 \mathrm{~nm}, \phi$ of $c a .60 \%, \tau$ of $2.34 \mathrm{~ns}$, and a ratio Trp57-chromophore of 0.41. In addition, there is a slight rise in emission of the band corresponding to the neutral form of the chromophore $(450 \mathrm{~nm})$. These changes might be attributed to several factors, namely i) the presence of the buffer that changes the FP-polymer interaction, ii) a change of the ionic strength in the TMPE region, in which the FP is stabilized, and iii) a change of the local $\mathrm{pH}$ at the surroundings of the protein backbone caused by the partial dehydration of the polymer mixture under vacuum.
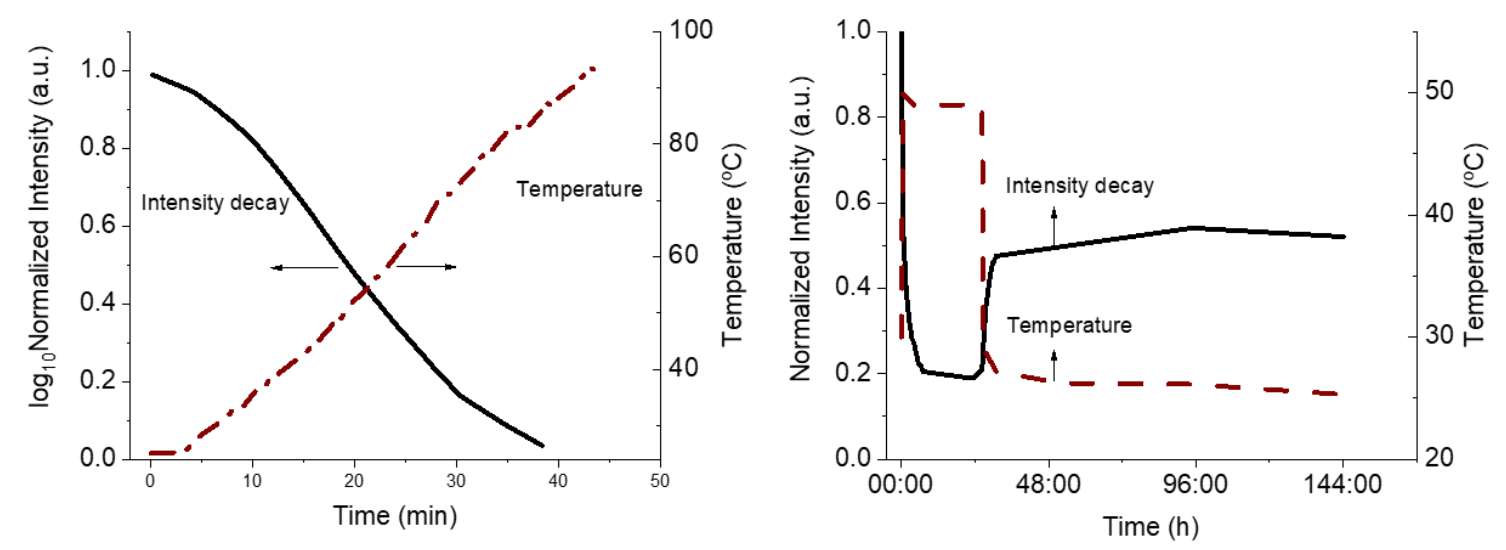

Figure 9. Emission behaviour over time of buffer-based FP-coatings upon increasing temperature (left) and at constant temperature $\left(50^{\circ} \mathrm{C}\right)$ for $24 \mathrm{~h}$ and in the ensuing cooling process (right).

The isothermal stability of the buffer-based FP-coatings was analyzed (Figure 9). Similar to buffer-free FP-coatings (Figure 2), an emission intensity decay was noted, showing a $T_{\mathrm{m}}$ of $50^{\circ} \mathrm{C}$, which suggests that the thermal properties of the polymer matrix rule the thermal behavior of the coating regardless the buffer composition. Likewise, the isothermal assay at $50^{\circ} \mathrm{C}$ shows a similar behavior to that of the buffer-free FP-coating (Figure 3). However, $t_{50 \%}$ is reduced to $1 \mathrm{~h}$ in concert with a more prominent thermal emission quenching, decreasing up to $20 \%$ of the initial emission intensity and a blue-shift of $\lambda_{\max }$ up to $514 \mathrm{~nm}$. In addition, a poor 
Submitted to

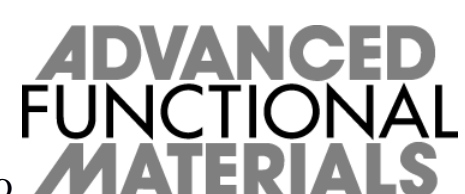

emission recovery even for the initial value at $50^{\circ} \mathrm{C}$ was noted. Hence, the use of phosphate buffer did not improve the FP thermal stability in the polymer matrix, as it was expected from the behavior observed in solution.

To shed light onto this behavior, spectroscopic features of the buffer-based FP-coatings were analyzed (Figure S11). Compared to the fresh buffer-based FP-coating, the ratio Trp57chromophore increased up to 0.8 , the $\phi$ was reduced to $30 \%$, and $\tau$ decreased to $1.92 \mathrm{~ns}$. In addition, a more intense band in the emission region of the neutral form of the chromophore is noted upon excitation at $375 \mathrm{~nm}$, confirming changes in the structure of the FP, and the presence of significant population of the neutral chromophore form upon heating. To further determine whether these changes are reversible, the heated buffer-based FP-coatings were rehydrated. As shown in Figure S12, the ratio Trp57-chromophore $(0.21)$ and $\lambda_{\max }(523 \mathrm{~nm})$ were recovered, and a $\phi$ of $50 \%$, slightly lower than those of the fresh buffer-based FP-coatings was measured, indicating that the temperature-induced deactivation process is partially irreversible when a buffer solution is used.
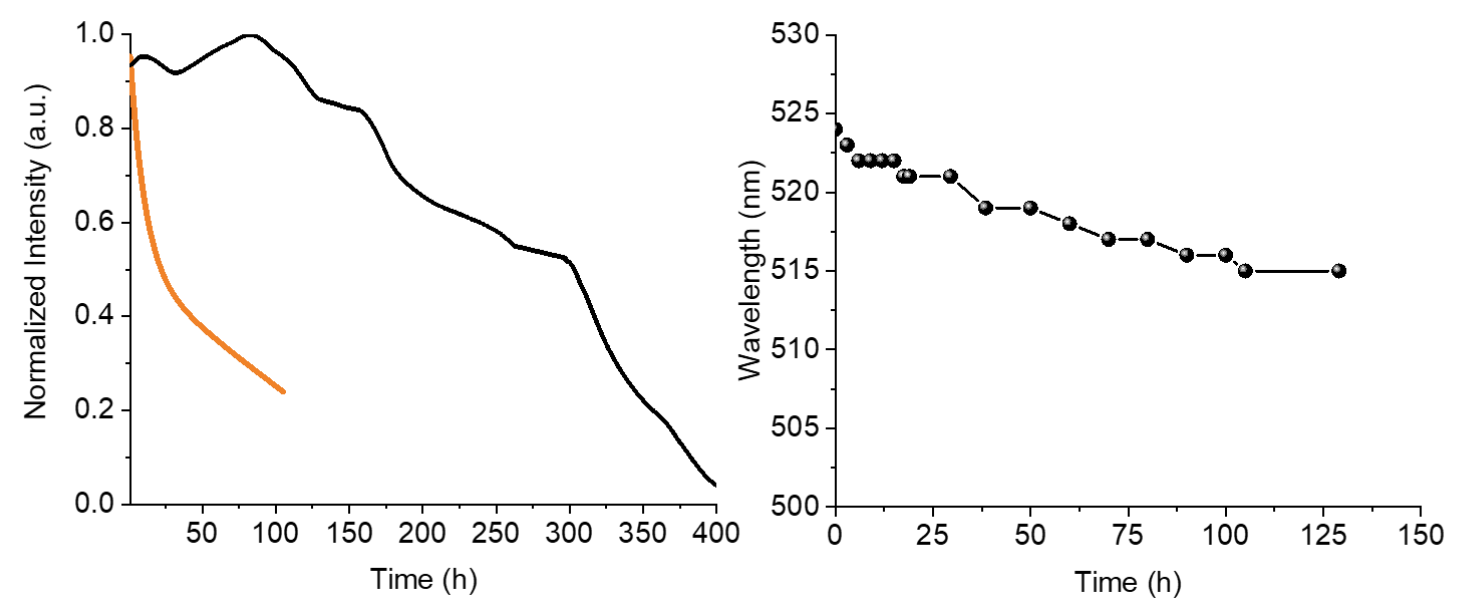

Figure 10. Stability of a buffer-based (orange) and buffer-free (black) FP-coating in remote a Bio-HLED architecture $\left(2 \mathrm{~cm} ; \lambda_{\mathrm{exc}}=450 \mathrm{~nm}\right)(\mathrm{left})$. Change of the emission of buffer-based FPcoating Bio-HLEDs over time (right). 


\section{Submitted to}

Concerning the photo-induced deactivation mechanism, we monitored the emission decay of a buffer-based FP-coating in remote Bio-HLEDs $(2 \mathrm{~cm})$ architecture - Figure 10. In stark contrast to buffer-free FP-coating Bio-HLEDs, the FP-coating emission decay obeys an exponential behavior with $t_{50 \%}$ of $23 \mathrm{~h}$ along with a continuous change in $\lambda_{\max }$ from $523 \mathrm{~nm}$ to $515 \mathrm{~nm}$. Importantly, the use of buffers promotes emission from an excited state at $523 \mathrm{~nm}$. Interestingly, in buffer-free FP-coatings, this $\lambda_{\max }$ value indicated the beginning of the irreversible change of the charge state of the chromophore (Table 1 and Figures 7 and S13). Hence, the use of standard buffer compositions does not improve the device stability when operating at high applied currents. However, this just points out the need to optimize them to stabilize FP into a polymer network for lighting applications.

To confirm this deactivation mechanism, the spectroscopic properties after continuous irradiation were also compared to those of the fresh buffer-based FP-coating (Figure S13). Here, the ratio Trp57-chromophore was similar to that of the heated buffer-based FP-coating (0.8), confirming the partial denaturation of the $\beta$-barrel. In addition, low $\phi$ values $(20 \%)$, $\tau$ values of $2.0 \mathrm{~ns}$, and a prominent emission band corresponding to the neutral chromophore were noted. Rehydration of the FP-coating was also performed to confirm the non-reversible denaturation of the protein (Figure S14). As expected, no recovery of the emission features was noted. This is also confirmed by EIS assays (Figure S15), where similar trends, that is, reduction of $R_{\mathrm{p}}$ and $\varepsilon$ compared to fresh buffer-based FP-coatings for both isothermal and irradiated FP-coatings, are found. These parameters are not significantly changed after hydration, implying that an irreversible structural change of the FP has taken place.

All these results point out that the use of one of the most common buffers to stabilize FPs in solution is not effective against the temperature- and photo-induced deactivation of the FP in polymer matrices applied in Bio-HLEDs. Quite likely, the FP-polymer interaction is 
Submitted to
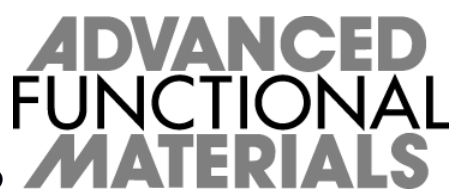

weakened, leading to a quick and irreversible structural change of the FP that is also associated to a change of the chromophore excited state.

\section{Conclusions}

This work deciphers the origin of the FP deactivation mechanism in Bio-HLEDs that feature stabilities of $<1$ minute operating at high applied currents. Under these conditions, thermal-deactivation is the prime mechanism, since the FP-coatings reach temperatures of $c a$. $60^{\circ} \mathrm{C}$, corresponding to the melting temperature of the polymer matrix. The temperature increase is attributed to the continuous excitation of the FPs that act as hot spots melting the surrounding polymer, while the elastomeric nature of the material is still preserved. As a result, there is a weakening of the interaction between the FP and the quasi-melted polymer, promoting changes in the charge of the chromophore and/or the partial denaturation of the $\beta$-barrel. Therefore, the thermal properties of the polymer matrix are instrumental to reduce the thermally-induced deactivation process in 'on chip' Bio-HLEDs. To further determine the binding affinity of the FP-polymer, we are currently carrying out NMR and microcalorimetry assays. However, it is important to notice that the protein backbone is not totally denatured upon both thermal stress as determined by CD assays, while the deactivation of the FP-coating should be related mostly to those changes in the chromophore environment.

Beside this aspect, the temperature-induced deactivation is easily circumvented changing to a remote device architecture, achieving stabilities $>300 \mathrm{~h}$ at the same operating conditions. Here, only the photo-induced deactivation mechanism that leads to a dynamic change of the excited state nature is operative. In short, there are two slow and reversible processes related to a partial dehydration of the FP leading, to small changes in the FP-coating emission band during $c a .185 \mathrm{~h}$. This is followed by a quick and irreversible deactivation process associated to a partial conformational change in the chromophore local environment that modifies the overall charge distribution of the chromophore cavity, leading to an 


\section{Submitted to}

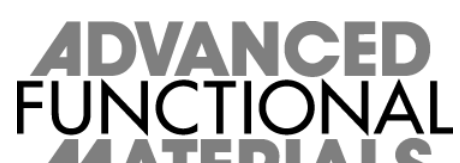

irreversible change of the nature of the emitting excited state, leading to a fully deactivation of the high-emissive ionic and the remaining of those of the low-emissive neutral form. Similar to the temperature-induced deactivation, the emission bleaching upon continuous excitation must not be associated to a loss of the secondary structure of the protein. Therefore, it is instrumental to focus on the fine-tuning of the local environment surrounding the chromophore to increase device stability. Striking enough, the use of phosphate-based buffers to preserve the ionic form of the FP chromophore leads to a detrimental decrease of the device stability up to $c a .20 \mathrm{~h}$ operating at the same conditions. This highlights that conventional additives used in biological applications (aqueous solution) might not be effective in polymer matrices used as packaging systems for LEDs, opening an interesting research field to stabilize FPs in solid-state devices. In this respect, we would like to point out that the comparison shown in this work might be considered as an attempt to highlight the need of optimizing buffers - type, concentration of salts and other additives - with respect to both coating formation and Bio-HLED performance.

Overall, this work asserts that the optimum design of the FP-coatings for highly stable Bio-HLEDs. However, other more relevant key aspects, such as thermal features of the polymer matrix, buffers and/or additives, device design, and FP emission deactivation, still need to be addressed to realize highly efficient and stable Bio-HLEDs. Work along these lines is currently in progress in our research groups.

\section{Experimental section}

\subsection{Materials}

All chemicals were purchased from Sigma Aldrich and used without further purification. The branched and linear poly(ethylene oxide) compounds (i.e., trimethylolpropane ethoxylate (TMPE) with Mn. of 450 mol. wt. and linear poly(ethylene oxide) (l-PEO) with Mn. of $5 \times 10^{6} \mathrm{~mol}$. wt). To prepare phosphate buffer $\mathrm{pH} 8,50 \mathrm{mM}$, sodium phosphate monobasic 


\section{Submitted to}

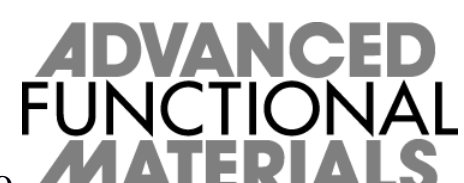

(>99\%) of 119.98 mol. wt., and sodium phosphate dibasic (>99\%) of 141.96 mol. wt. were purchased. The enhanced eGFP with 27624.22 mol. wt., a concentration of $10 \mathrm{mg} / \mathrm{mL}$ in MiliQ water, and a purity $>90 \%$ was as described below.

\subsection{Protein expression and purification}

eGFP was expressed in Escherichia coli DH10b cells grown in Luria-Bertani (LB) liquid medium for $24 \mathrm{~h}$ at $37^{\circ} \mathrm{C}$. The cells were harvested by centrifugation at $4500 \mathrm{rpm}$ for 15 min and the pellets were resuspended in lysis buffer $(300 \mathrm{mM} \mathrm{NaCl}, 50 \mathrm{mM}$ Tris $\mathrm{HCl} \mathrm{pH}$ 7.4) with $1 \mathrm{mg} / \mathrm{ml}$ lysozyme, $5 \mathrm{mM} \beta$-mercaptoethanol and $5 \mu \mathrm{l}$ of DNase stock solution. The lysate was sonicated 5 min with $30 \mathrm{sec}$ of intervals and $40 \%$ of amplitude, and then centrifuged at $10000 \mathrm{rpm}$ for $45 \mathrm{~min}$. The supernatant solution was loaded into $\mathrm{Ni}^{2+}$ HisTrap $^{\mathrm{TM}}$ column, and the protein was eluted with $300 \mathrm{mM} \mathrm{NaCl}, 300 \mathrm{mM}$ imidazole, $50 \mathrm{mM}$ Tris $\mathrm{HCl} \mathrm{pH}$ 7.4. The fractions containing the protein were pooled and dialyzed into Milli-Q water. The purity of the samples was determined by SDSPAGE and spectrometrically. The protein was concentrated to $10 \mathrm{mg} / \mathrm{ml}$ then stored in aliquots at $-20^{\circ} \mathrm{C}$.

\subsection{Preparation of the FP-coatings}

The FP-coatings were prepared as follows. The eGFP solution $(0.45 \mathrm{mg})$ in a final volume of $300 \mu \mathrm{L}$ of either buffer-free or phosphate-based buffer water solution was prepared. A mixture of 4:1 ratio with TMPE:PEO was added and stirred (300 rpm) under ambient conditions overnight, forming a hydrogel. The final rubber-like material was achieved after a vacuum process from 200 to 3 mbar for $4 \mathrm{~h}$. The FP-free coatings were prepared following the above description using a buffer-free water solution without eGFP for reference purposes. The rehydration process was carried out as follows. The FP-coatings were cut into pieces and afterwards embedded in either buffer-free or phosphate-based buffer water solutions in a proportional volume regarding the total mass of the coating. They were left for $1 \mathrm{~h}$ at room 


\section{Submitted to}

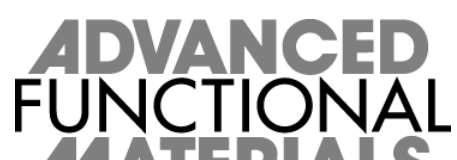

conditions until the water solution was adsorbed to the naked eye. Then it was put through the above discussed vacuum process to obtain the final rubber-like coating.

\subsection{Device preparation and characterization}

The FP-coatings were placed at different distances from the $450 \mathrm{~nm}$ LED (Winger Electronics) and irradiated at $200 \mathrm{~mA}$ at room conditions. The Bio-HLEDs were characterized using a Keithley 2400 as a current source, while the changes in the electroluminescence spectrum were monitored using an AVS-DESKTOP-USB2 (Avantes) in conjunction with a calibrated integrated sphere Avasphere 30-Irrad, while the changes in the FP-coating temperature were monitored using a thermographic camera T430sc (FLIR).

\subsection{Characterization techniques}

The photophysical studies were carried out using a FS5 Spectrofluorometer (Edinburgh Instruments) with the SC-10 module for solid samples, the SC-30 Integrating Sphere to determine $\phi$, and the $375 \mathrm{~nm}$ time-correlated single photo-counting or TCSPC (64.3 ps pulse width) module to determine $\tau$. The measurements were performed at room temperature. The EIS analysis was performed using cleaned fluorine-tin oxide (FTO) coated glass substrates to sandwich the FP-coatings. The Nyquist spectra were measured with the Metrohm $\mu$ AutolabIII potentiostat equipped with a frequency response analyser module (FRA2). The AC signal amplitude was set to $0 \mathrm{mV}$, modulated in a frequency range from 1 to $10^{6} \mathrm{MHz}$. The Nova 2.1 software was used to obtain the parameters from the equivalent circuit. With this data, the polarization resistance of the bulk $\left(R_{\mathrm{p}}\right)$ was directly obtained. The dielectric constant $(\varepsilon)$ was calculated with the formula $\varepsilon=C d /\left(\varepsilon_{0} A\right)$, where $C$ is the effective capacitance, $d$ the thickness of the layer, $\varepsilon_{\mathrm{o}}$ is the vacuum permittivity $\left(8.85 \times 10^{-12} \mathrm{~F} / \mathrm{m}\right)$, and $A$ is the active area of the device $\left(6.25 \mathrm{~mm}^{2}\right)$. All the measurements were carried out at room conditions.

The FP-coatings were also measured under constant heating from 25 to $120^{\circ} \mathrm{C}$, with a temperature ramp of $2^{\circ} \mathrm{C} / \mathrm{min}$, in a heating plate in the dark. Additionally, the changes of the 
Submitted to

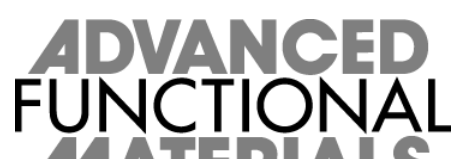

emission were also monitored at a constant heating of $50^{\circ} \mathrm{C}$ for $24 \mathrm{~h}$. Both, the devices after the photo- and thermal-processes were spectroscopically analysed using the spectrofluorometer above-mentioned. Emission spectra under excitation of 275 and $375 \mathrm{~nm}$ as well as $\phi$ were measured. Circular dichroism (CD) measurements to determine the secondary structure of the eGFP within the polymeric materials were performed using a Jasco J-815 spectropolarimeter. The FP-coatings were measured over quartz slides. The CD spectra were acquired at $1 \mathrm{~nm}$ increments and 10 seconds average time over a wavelength range of 190 to $260 \mathrm{~nm}$. The time decay values were monitored as mentioned in section 1.5. The data was then adjusted to a biexponential decay fit using Origin $8 \mathrm{~b}$. To calculate the average lifetime for each FP-coating, the following equation was used: ${ }^{[78]}$

$$
<\tau>_{f}=\frac{\int_{0}^{x} t \sum a_{i} \exp \left(-\frac{t}{\tau_{i}}\right) d t}{\int_{0}^{x} t \sum a_{i} \exp \left(-\frac{t}{\tau_{i}}\right) d t}=\frac{\sum a_{i} \tau_{i}^{2}}{\sum a_{i} \tau_{i}}
$$

Where $\mathrm{a}_{\mathrm{i}}(\lambda)$ is the amplitude fractions and $\tau_{\mathrm{i}}$ are the lifetimes.

\section{References}

[1] V. Fernández-Luna, P. B. Coto, R. D. Costa, Angew. Chem., Int. Ed. 2017, 57, 8826.

[2] E. Fresta, V. F. Luna, P. B. Coto, R. D. Costa, Adv. Funct. Mater. 2018, 28, 1707011.

[3] US Department of Energy (2019, January 5). Retrieved from https://energy.gov/sites/prod/files/2017/09/f37/ssl_suggested-researchtopics_sep2017.pdf 2017.

[4] McKinsey \& Company (2019, January 5). Retrieved from https://www.mckinsey.com/business-functions/operations/o 2012.

[5] J. Casamayor, D. Su, Z. Ren, Light. Res. Technol. 2017, 50, 801.

[6] JRC Scientific and policy reports (2019, January 5). Retrieved from 
Submitted to

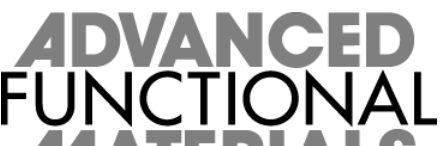

https://setis.ec.europa.eu/sites/default/files/reports/JRC-report-Critical-Metals-Energy-

Sector.pdf 2013.

[7] M. Bergamos, R. Höltig, In Recycling options for LEDs and LED products. Electronics Goes Green 2012+; IEEE: Berlin, Germany, 2012.

[8] M. Hatori, C. Gronfier, R. N. Van Gelder, P. S. Bernstein, J. Carreras, S. Panda, F. Marks, D. Sliney, C. E. Hunt, T. Hirota, T. Furukawa, K. Tsubota, npj Aging Mech. Dis. 2017, 3, 9.

[9] I. Jaadane, P. Boulenguez, S. Carré, M. Savoldelli, C. Martinsons, A. Torriglia, Free Radic. Biol. Med. 2015, 84, 373.

[10] J. Hye Oh, S. Ji Yang, Y. Rag Do, Light Sci. Appl. 2014, 3, e141.

[11] F. Behar-Cohen, C. Martinsons, F. Viénot, G. Zissis, A. Barlier-salsi, J. P. Cesarini, O. Enouf, Prog. Retin. Eye Res. 2011, 30, 239.

[12] D. Van Norren, T. G. M. F. Gorgels, Photochem. Photobiol. 2011, 87, 747.

[13] European comission, scientific committees a) (2019, January 5) Retrieved from https://ec.europa.eu/health/scientific_committees/scheer/docs/scheer_q_002.pdf b) (2019, January 5) Retrieved from https://ec.europa.eu/health/scientific_committees/emerging_e.

[14] T. Kosuge, X. Zhu, V. M. Lau, D. Aoki, T. J. Martínez, J. S. Moore, H. Otsuka, T. Kosuge, X. Zhu, V. M. Lau, D. Aoki, T. J. Martinez, S. Jeffrey, J. Am. Chem. Soc 2019, 141, 1898.

[15] J. Huang, J. Li, Y. Lyu, Q. Miao, K. Pu, Nat. Mater. 2019, DOI: 10.1038/s41563-0190378-4.

[16] Y. Zheng, H. Liu, J. Li, J. Xiang, M. Panmai, Q. Dai, Adv. Mater. 2019, DOI: 10.1002/adma.201901371.

[17] K. Vellaisamy, G. Li, W. Wang, C. Leung, D. Ma, Chem. Sci. 2018, 9, 8171. 
Submitted to
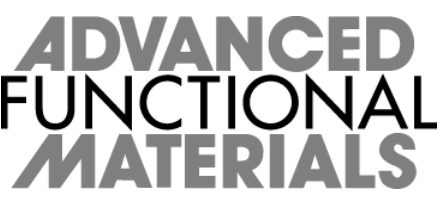

[18] L. Niklaus, S. Tansaz, H. Dakhil, K. T. Weber, M. Pröschel, M. Lang, M. Kostrzewa, P. B. Coto, R. Detsch, U. Sonnewald, A. Wierschem, A. R. Boccaccini, R. D. Costa, Adv. Funct. Mater. 2017, 27, 1601792.

[19] S. Nizamoglu, SDÜ Fen Bilim. Enstitüsü Derg. 2016, 20, 490.

[20] D. A. Press, R. Melikov, D. Conkar, E. N. Firat-Karalar, S. Nizamoglu, Nanotechnology 2016, 27, 45LT01.

[21] M. D. Weber, L. Niklaus, M. Pröschel, P. B. Coto, U. Sonnewald, R. D. Costa, Adv. Mater. 2015, 27, 5493.

[22] D. Zhou, H. Zou, M. Liu, K. Zhang, Y. Sheng, J. Cui, H. Zhang, B. Yang, ACS Appl. Mater. Interfaces 2015, 7, 15830.

[23] Y. Cui, T. Song, J. Yu, Y. Yang, Z. Wang, G. Qian, Adv. Funct. Mater. 2015, 25, 4796.

[24] C.-Y. Sun, X.-L. Wang, X. Zhang, C. Qin, P. Li, Z.-M. Su, D.-X. Zhu, G.-G. Shan, K.Z. Shao, H. Wu, Nat. Commun. 2013, 4, 2717.

[25] I. O. Huyal, U. Koldemir, T. Ozel, H. V. Demir, D. Tuncel, J. Mater. Chem. 2008, 18, 3568.

[26] H. Yoo, H. S. Jang, K. Lee, K. Woo, Nanoscale 2015, 7, 12860.

[27] N. J. Findlay, J. Bruckbauer, A. R. Inigo, B. Breig, S. Arumugam, D. J. Wallis, R. W. Martin, P. J. Skabara, Adv. Mater. 2014, 26, 7290.

[28] L. Niklaus, H. Dakhil, M. Kostrzewa, P. B. Coto, U. Sonnewald, A. Wierschem, R. D. Costa, Mater. Horiz. 2016, 3, 340.

[29] C. F. Aguiño, M. Lang, V. Fernández-Luna, M. Pröschel, U. Sonnewald, P. B. Coto, R. D. Costa, ACS Omega 2018, 3, 15829.

[30] J. He, J., Yang, S., Zheng, K., Zhang, Y., Song, J., Qu, Green Chem. 2018, 20, 3557.

[31] C. Ezquerro, E. Fresta, E. Serrano, E. Lalinde, J. García-Martínez, J. R. Berenguer, R. D. Costa, Mater. Horizons 2019, 6, 130. 
[32] R. Y. Tsien, Biochemistry 1998, 67, 509.

[33] C. P. Dietrich, A. Steude, M. Schubert, J. Ohmer, U. Fischer, S. Höfling, M. C. Gather, Adv. Opt. Mater. 2017, 5, 1600659.

[34] C. P. Dietrich, A. Steude, L. Tropf, M. Schubert, N. M. Kronenberg, K. Ostermann, S. Höfling, M. C. Gather, Sci. Adv. 2016, 2, e1600666.

[35] A. J. C. Kuehne, M. C. Gather, Chem. Rev. 2016, 116, 12823.

[36] T. M. Drane, H. Bach, M. Shapiro, V. Milner, Biomed. Opt. Express 2015, 6, 1885.

[37] M. C. Gather, S. H. Yun, Nat. Commun. 2014, 5, 5722.

[38] H. J. Oh, M. C. Gather, J.-J. Song, S. H. Yun, Opt. Express 2014, 22, 31411.

[39] A. Jonas, M. Aas, Y. Karadag, S. Manioglu, S. Anand, D. McGloin, H. Bayraktar, A. Kiraz, Lab Chip 2014, 14, 3093.

[40] M. C. Gather, S. H. Yun, Nat. Photonics 2011, 5, 3.

[41] N. Hendler, B. Belgorodsky, E. D. Mentovich, M. Gozin, S. Richter, Adv. Mater. 2011, $23,4261$.

[42] J. Gotta, T. Ben Shalom, S. Aslanoglou, A. Cifuentes-Rius, N. H. Voelcker, $A d v$. Funct. Mater. 2018, 28, 1706967.

[43] M. Sun, S. Qu, Z. Hao, W. Ji, P. Jing, H. Zhang, L. Zhang, J. Zhao, D. Shen, Nanoscale 2014, 6, 13076.

[44] H. Tetsuka, A. Nagoya, R. Asahi, J. Mater. Chem. C 2015, 3, 3536.

[45] I. Yuruker, S. U., Arik, M., Tamdogan, E., Melikov, R., Nizamoglu, S., Press, D. A., \& Durak, In Volume 3: Advanced fabrication and manufacturing; emerging technology frontiers; energy, health and water- applications of nano-, micro- and mini-scale devices; MEMS and NEMS; technology update talks; thermal management using micro channels, jets, sprays; ASME: San Francisco, California, USA, 2015.

[46] R. Melikov, D. A. Press, B. G. Kumar, I. B. Dogru, S. Sadeghi, M. Chirea, İ. Y1lgör, S. 
Nizamoglu, Sci. Rep. 2017, 7, 7258.

Submitted to

[47] N. Qi, B. Zhao, S.-D. Wang, S. S. Al-Deyab, K.-Q. Zhang, RSC Adv. 2015, 5, 50878.

[48] X. Wang, Y. Guo, Z. Li, W. Ying, D. Chen, Z. Deng, X. Peng, RSC Adv. 2019, 9, 9777.

[49] M. S. P. Reddy, C. Park, Sci. Rep. 2016, 6, 32306.

[50] K. M. Dean, J. L. Lubbeck, J. K. Binder, L. R. Schwall, R. Jimenez, A. E. Palmer, Biophys. J. 2011, 101, 961.

[51] G. Donnert, C. Eggeling, S. W. Hell, Nat. Methods 2007, 4, 81.

[52] U. Haupts, S. Maiti, P. Schwille, W. W. Webb, Proc. Nat. Acad. Sci. U. S. A. 1998, 95, 13573.

[53] R. M. Dickson, A. B. Cubitt, R. Y. Tsien, W. E. Moerner, Nature 1997, 388, 355.

[54] S. Habuchi, M. Cotlet, T. Gensch, T. Bednarz, S. Haber- Pohlmeier, J. Rozenski, G.

Dirix, J. Michiels, J. Vanderleyden, J. Heberle, F. C. De Schryver, J. J. Hofkens, J. Am. Chem. Soc. 2005, 127, 8977.

[55] J. J. Van Thor, T. Gensch, K. J. Hellingwerf, L. N. Johnson, Nat. Struct. Biol. 2002, 9, 37.

[56] A. M. Bogdanov, E. A. Bogdanova, D. M. Chudakov, T. V. Gorodnicheva, S.

Lukyanov, K. A. Lukyanov, Nat. Methods 2009, 6, 859.

[57] C. C. David, P. Dedecker, G. D. Cremer, N. Verstraeten, C. Kint, J. Michiels, J. Hofkens, Photochem. Photobiol. Sci. 2012, 11, 358.

[58] R. Ando, H. Mizuno, A. Miyawaki, Science (80-. ). 2004, 306, 1370.

[59] K. Okabe, R. Sakaguchi, B. Shi, S. Kiyonaka, Pflugers Arch. Eur. J. Physiol. 2018, $470,717$.

[60] J. S. Donner, S. A. Thompson, C. Alonso-Ortega, J. Morales, L. G. Rico, S. I. C. O. Santos, R. Quidant, ACS Nano 2013, 7, 8666. 
Submitted to

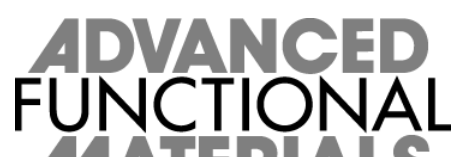

14 A 14 a

[61] S. Kiyonaka, T. Kajimoto, R. Sakaguchi, D. Shinmi, M. Omatsu-Kanbe, H. Matsuura, H. Imamura, T. Yoshizaki, I. Hamachi, T. Morii, Y. Mori, Nat. Methods 2013, 10, 1232.

[62] M. Nakano, Y. Arai, I. Kotera, K. Okabe, Y. Kamei, T. Nagai, PLoS One 2017, 12, 1.

[63] N. Inada, N. Fukuda, T. Hayashi, S. Uchiyama, Nat. Protoc. 2019, 14, 1293.

[64] N. H. Lyndby, M. Kuhl, D. Wangpraseurt, Sci. Rep. 2016, 6, 1.

[65] G. Jung, S. Mais, A. Zumbusch, C. Bräuchle, J. Phys. Chem. A 2000, 104, 873.

[66] W. Weber, V. Helms, J. A. McCammon, P. W. Langhoff, Proc. Nat. Acad. Sci. USA 1999, 96, 6177.

[67] Z. Ganim, M. Rief, Proc. Natl. Acad. Sci. USA 2017, 114, 11052.

[68] W. W. Ward, In Green fluorescent protein: properties, applications, and protocols; Chalfie, S., Kein, M., Ed.; John Willey \& Sons, Inc.: Hoboken, N.J, 2006; pp. 39-66.

[69] M. Zimmer, Chem. Rev. 2002, 102, 759.

[70] S. H. Bokman, W. W. Ward, Biochem. Biophys. Res. Commun. 1981, 101, 1372.

[71] P. Dedecker, F. C. De Schryver, J. Hofkens, J. Am. Chem. Soc. 2013, 135, 2387.

[72] F. W. J. Teale, G. Weber, Biochem. J. 1954, 65, 476.

[73] Principles of Fluorescence Spectroscopy; Lakowicz, J. R., Ed.; Springer US, 2006.

[74] A. Ghisaidoobe, S. Chung, Int. J. Mol. Sci. 2014, 15, 22518.

[75] N. V. Visser, J. W. Borst, M. A. Hink, A. Van Hoek, A. J. W. G. Visser, Biophys. Chem. 2005, 116, 207.

[76] D. S. Patil, K. Shimakawa, V. Zima, T. Wagner, J. Appl. Phys. 2014, 115, 143707.

[77] C. Vessoni Penna, M. Ishii, A. Pessoa junior, O. Cholewa, Appl. Biochem. Biotechnol. 2004, 113, 469.

[78] A. Sillen, Y. Engelborghs, Photochem. Photobiol. 1998, 67, 475. 


\section{FUNCANCED \\ Submitted to 14 A}

